\title{
Research on the Transformation and Promotion of Resources and Achievements of National Vocational Skills Competition
}

\author{
Liu Liying* (Corresponding Author) \\ College of Public Management \\ Tianjin Vocational Institute \\ Tianjin, China \\ liuliying0718@163.com \\ Wang Shuwen \\ College of Public Management \\ Tianjin Vocational Institute \\ Tianjin, China \\ 739796426@qq.com
}

\author{
Yang Renjie \\ College of Engineering and Technology \\ Tianjin Agricultural University \\ Tianjin, China \\ rjyang1978@163.com \\ Zhao Yue \\ College of Public Management \\ Tianjin Vocational Institute \\ Tianjin, China \\ 49004988@qq.com
}

\begin{abstract}
On the basis of making full use of the advanced ideas and models of the world skills competition, the overall situation of the transformation and promotion of higher vocational skills competition was surveyed in terms of preliminary investigation. The difficulties and problems in the transformation and promotion of resources were summarized. And the reasons for the difficulties in the transformation of resources were analyzed. Combined with the achievements of China's outstanding case resources transformation and promotion of experience, the universal countermeasures for the transformation and promotion of the national vocational skills competition were put forward in this paper. The resource library of vocational skills competition was formed, including scientific transformation of teaching resources, social resources and excellent talent promotion. The mechanism of the transformation of resources of vocational skills competition was constructed. This research provides the theoretical basis for the transformation and promotion of higher vocational skills competition.
\end{abstract}

Keywords-National Vocational Skills, Transformation and Promotion, Resources and Achievements, Vocational Colleges, Resource Sharing Platform

\section{INTRODUCTION}

For national vocational skills competition, the Ministry of education requires that all resources in the process of competition should be shared, including technical documents, competition platform, test database, video data, and so on. Vocational skills competition is more effective for professional construction and teaching reform. Based on the platform of national vocational education reform and innovation demonstration, the main stadium of Tianjin focused on strengthening the construction of the platform for the transformation of the competition achievements resources in 2015 years. Good experience, results, models are summarized and formed the resources conversion library of vocational skills

\footnotetext{
1. Tianjin Educational Science and Planning Project (VE3147).

2. Education Reform and Innovation Development Funds of Tianjin Agricultural University (20170202).
}

competition. Furthermore, competition results really benefit teachers and students. Thus, the reasonable choice of competition resources, scientific transformation of teaching resources and social resources, full propaganda of competition results, construction of resource transformation mechanism, perfect system and mode of competition resources conversion, which are urgent to solve task of national vocational skills competition [1].

In order to solve the above problems, it is necessary to make a detailed investigation of the relevant policies and regulations, the implementation of the specific content and the steps of transformation and promotion of resources and achievements of national vocational skills competition. The existing problems are analyzed from the survey results, and suggestions are put forward for the transformation and application of resources and achievements of vocational skills competition.

\section{ACHIEVING GOOD EFFECT OF THE TRANSFORMATION AND PROMOTION OF COMPETITIVE RESOURCES}

\section{A. Government supporting}

Government strongly supports the transformation and promotion of higher vocational skills competition. Before each contest, the Ministry of education will compile the competition system, which will have the content, and requirements of specific length relates to the competition of resource transformation [2]. Generally speaking, the main content of the transformation of resources is: test banks; competition skill assessment; assessment environment description; audio and video recording; comments of judges, referees and expert; interview of excellent players and teachers.

The transformation of resources and achievements should comply with the industry standard, with curriculum standards, skills characteristics, showing competition advantage, meeting 
the teaching needs, reflecting the sharing of teaching resources, showing advanced level of occupation education. The transformation of resources and achievements should include basic resources and expand resources, reflecting the characteristics of competition skills assessment.

1. Basic resources should include style display, skill outline, teaching unit, teaching resources.

2. Expand resources should include comment video, interview video, test database, case library, material library, and so on resources.

Thus it can be seen that the Ministry of education has clear instructions for the definition and transformation of the competition resources. And the transformation of resources is mature and feasible in the system construction.

\section{B. Colleges participating}

At present, the higher vocational colleges actively organize and participate in all kinds of skills competition, and promote the effective integration of higher vocational education and post [3]. The concept and achievement of skills competition has been successfully transformed into available resources, improving the quality of education and teaching, training a large number of high-quality skilled personnel. Some colleges have set up a program to transform competition item into skill learning and teaching information resources, and been formed a series of comprehensive training program of teaching. The problems of relation of "doing" and "learning", knowledge and skills, theory and practice have been resolved specially, and built matching teaching resources [4].

With the aid of skills competition, some colleges promote and revise personnel training programs for training students with scientific maintenance diagnosis. Students are guide to form standardized operating habits, and pay attention to professional theory and skills training. The skills training methods and diagnostic thinking, the actual operation of the norms and team cooperation are introduced into the classroom teaching through repeated discussions, and gradually explore and implement.

With the aid of skills competition, some colleges develop massive open online courses (MOOC), video resources, text resources and image resources, for standardizing the implementation of curriculum design and content. Through the transformation of the resources and achievements of skills competition, the reform of professional education teaching can be effectively promoted. The resources and achievements of skills competition can be transformed into the MOOC resources, which can create a more independent way of learning for the students and improve the quality of talents [5].

\section{BotTLENECKS AND PROBLEMS TO BE SOLVED IN THE TRANSFORMATION AND PROMOTION OF RESOURCES}

\section{A. No official or authoritative sharing platform for the transformation of resources}

Participating in skills competition, colleges need to sign up and view information in the official website of national vocational skills. However, there is no information of the transformation of resources sharing in the official website. The participating teachers are not satisfied with sharing mechanism of vocational skills (Fig.1).

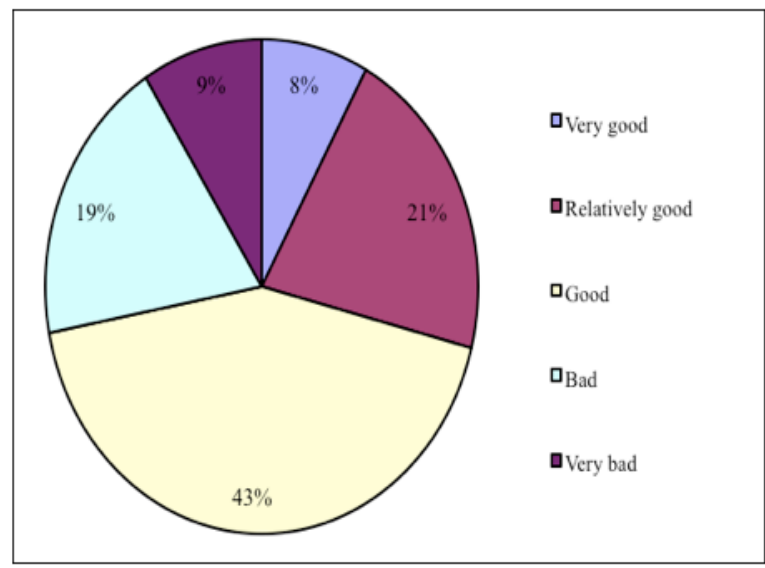

Fig. 1. The analysis of overall satisfaction of resource sharing mechanism

In the course of each tournament, teacher forum agenda is arranged to provide a platform to help teachers with communicate information. However, in practice, this agenda is basically arranged in the race day. Teachers are most concerned about the situation of the students, not enthusiastic for teachers' forum. A large part of the teachers do not take part in the activity (Fig.2). Teacher forum has also become a platform of promoting products for sponsoring companies.

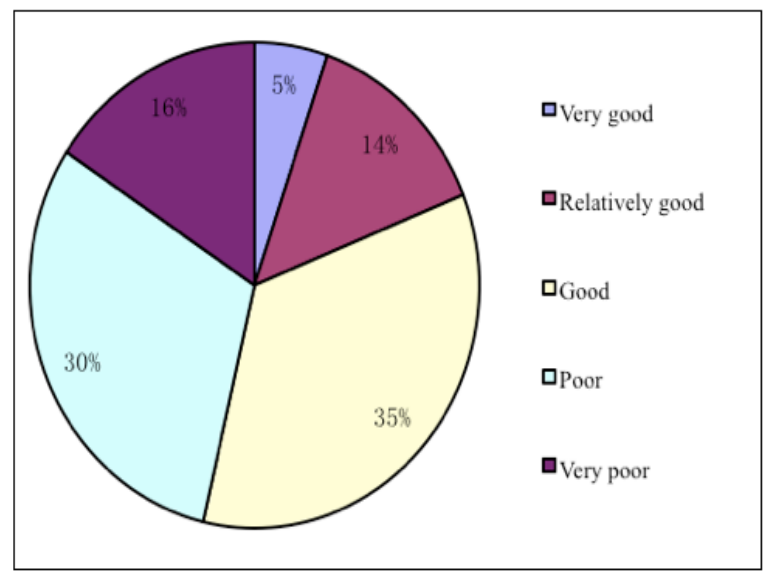

Fig. 2. The analysis of overall satisfaction of competition atmosphere and teacher discussion

\section{B. No implementation of transformation scheme of resources}

For example, some students participated in the national skills competition of stenography specialty in Tianjin Vocational Institution. After the competition, in the submission of relevant materials of resource conversion, because of no implementation of transformation scheme of resources, the transformation and promotion of the competition resources are unsatisfactory. Due to lack of resources, teachers can only adopt a single method to guide students to prepare the national skills competition (Fig.3). 


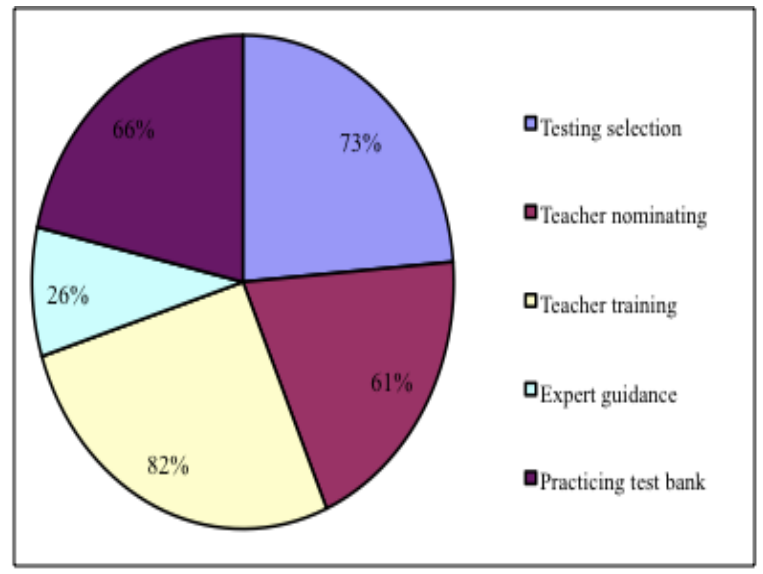

Fig. 3. The analysis of guidance methods of preparing skills competition

\section{No good convergence of skills competition and college teaching}

At present, for most of the colleges, the contestants are selected for training from good students. Compared with other students, these candidates are very difference in learning content, schedule, the degree of difficulty. In other words, when the contestants preparing the skills competition, most of the students are learning the knowledge and skills that are not relevant to the skills competition, which is also reflected in our questionnaire(Fig.4).

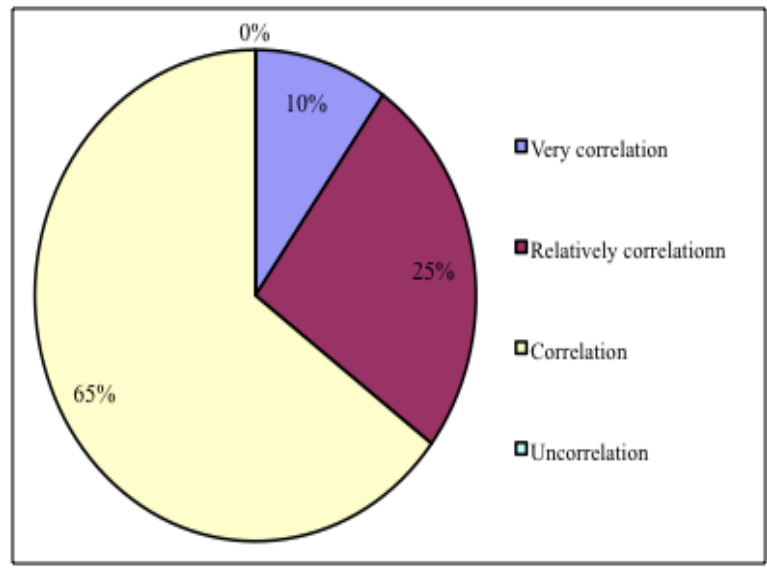

Fig. 4. The analysis of convergence degree of skills competition and college teaching

\section{STUDY ON THE TRANSFORMATION AND PROMOTION OF SKILLS COMPETITION RESOURCES}

\section{A. Constructing resource sharing platform}

With the rapid development and wide application of electronic information technology, the level of social information continuously improving, the data information has become an indispensable valuable resource and wealth in modern society. A platform can be established for unified integration of resources, transformation, sharing, exchanging in official website of national vocational skills. The various disciplines of audio, video and text, materials and other resources should be integrated [6]. With the sharing resource platform as the carrier, the network service system as the support, a big platform should be established for skills competition and the combination of resources, online and offline competition resources. On the basis of the platform, combined with the development of the characteristics and requirements of the skills competition, the management and utilization of the platform is planned and organized with the purpose of the transformation and promotion of resources, so as to achieve the goal of resource sharing, convenient service and promotion. Construction platform should meet the following functions:

1. Directory services: the platform background management personnel can carry on the unified management of the directory information of the shared resources, and provide the resources retrieval service for the public.

2. Basic resource sharing service: the platform can collect all kinds of audio, video, text and other basic resources and expand resources, and provide shared services for teachers and students.

3. Supervision service: Sharing situations of all resources are monitored.

\section{B. Deepening curriculum teaching}

In order to better carry out the transformation and promotion of resources, higher vocational colleges should combine the relevant assessment points and the professional occupation in the guidance of students participating skills competition. The core of vocational training courses is refined, so as to provide the basis for the development of curriculum standards. This can be the core content of the competition into the curriculum teaching, not only deepen the reform of the course content, but also to be able to teach the competition resources to all students [7].

In this aspect, professional secretarial stenography has gained some experiences in Tianjin Vocational Institute. According to the high requirements of the skills competition, refining the core competencies, the core curriculum is identified in terms of the characteristics of graduates' employment. And the new talent-training program is revised according to the technical requirements of professional posts. In accordance with the curriculum standards of the working process, the task driven and project oriented teaching model are implemented. According to the requirements and characteristics of stenography post group, combined with the core competition project, the task will be reasonable decomposition and integration by selecting typical tasks as teaching content and learning tasks. The projects as the carrier of the real work tasks are implemented through introduction of the actual project or task into the daily teaching. The audio and video, the teaching resources database must be constructed for competition service. At the same time, multimedia aided teaching resources are developed. 


\section{Deepening the reform of teaching mode}

1) Establishing professional associations for enriching teaching mode

For students of professional secretarial stenography in Tianjin Vocational Institute, some excellent students are selected to get into stenography association- "Ten Liquid" under the encouragement of teachers, and students' autonomous enrollment way. The associations can provide quality stenography services for faculties, schools and social through each other than mutual learning, mutual discussion and common progress. Students not only master their own professional knowledge, but also to organize and coordinate the students to complete the training program. In addition, students can actively organize the activities through association-"Ten Liquid" in extra-curricular activities, and extend the professional knowledge of the study from the class to the outside, to create a good learning atmosphere.

\section{2) Enhancing teaching effect}

Based on skills competition platform, professional training base can be developed. The studio model of colleges and wellknown enterprises are constructed, and run long-term cooperative management mechanism. In the studio, the technical skills and professional quality are trained reflecting the production. The studio can be composed of employees, teachers and students, not only has the functions to complete the relevant industries and jobs, but also has the function of guiding the students to complete the task of skill training. Through the actual project consulting services, so that students can contact the work in advance, in order to enhance the students' professional quality. At the same time, full-time teachers also have the opportunity to contact the actual case, the accumulation of practical experience [8].

On the basis of skills competition platform, professional off campus training base can be developed. Students of professional secretarial stenography have made remarkable achievements in Tianjin Vocational Institute. Students have successfully provided quality services for Tianjin Municipal Education Commission and the Tianjin second intermediate people's court. The professional counterparts, the higher the level, the influence of large training base are constructed. And the achievements of skills competition have been extended for serving the community.

\section{CONCLUSIONS}

Vocational college skills competition promotes the process of vocational education. In order to better play the role of skills competition, the resources of achievements are transformed to deepen the reform of the professional to provide effective ways and means to play a leading role in the skills competition and radiation. The quality of skilled personnel training can be improved by building school enterprise cooperation platform. At the same time, the skills competition model has a high degree of maneuverability, typicality, portability and promotion. We should improve the long-term mechanism of competition, increase the intensity of the results of the skills competition and the pace of transformation, to promote the sustainable development of skills competition and vocational education.

\section{ACKNOWLEDGMENT}

This work was financially supported by Tianjin 13th FiveYears Educational Science and Planning Project (VE3147) and the Education Reform and Innovation Development Funds of Tianjin Agricultural University (20170202).

\section{REFERENCES}

[1] Jin Runcheng. Strategic thinking on the promotion of vocational education development by competition of national vocational college skill [J]. Eductional Research, 2011, 9:56-61. (In Chinese)

[2] Qin Hong, Hu Jie. Research on the influence of national vocational college skill competition on vocational education ideas and concepts[J]. Eductional Research, 2011, 11:76-81. (In Chinese)

[3] Zhang Amin, Xu Dazhen. The current situation analysis and countermeasure research of national vocational students skills competition[J]. Higher Vocational Education-Journal of Tianjin Vocational Institute, 2013, 5: 13-15. (In Chinese)

[4] Shi Hong, Zhou Qun. Experimental enlightenments of the national vocational skills competition to the reform of higher vocational education in Western Regions [J]. Vocational and Technical Education, 2012, 20: 51-54. (In Chinese)

[5] Cai Yanna, Xu Ziyuan. The MOOC development and application which transformed from the achievements of the SCM vocational skills competition [J]. Journal of Juamjusi Education Institute. 2016, 7: 220221. (In Chinese)

[6] Tang Xiaohua, Lv Jingquan. The development of three-dimensional teaching resources and skills competition design in national skills competition[J]. Chinese Vocational and Technical Education, 2012, 35:81-84+88. (In Chinese)

[7] Cao Zhi. Accelerate the skills competition achievement transformation, deepen the course reform of the engineering cost majors [J]. Journal of Tianjin Vocational Institutes, 2014, 12:107-110. (In Chinese)

[8] Liu Dongju, Tang Guoming, Chen Xiaoxi, et al. Study on the influence of skills competition of national vocational schools on teaching reform and development[J]. Vocational and Technical Education, 2015, 10: 30 34. (In Chinese) 